\title{
Physicochemical Properties, Fatty Acid Composition, Volatile Compounds of Blueberries, Cranberries, Raspberries, and Cuckooflower Seeds Obtained Using Sonication Method
}

\author{
Dorota Bederska-Łojewska ${ }^{1}$, Marek Pieszka ${ }^{1, *}{ }^{\mathbb{D}}$, Aleksandra Marzec ${ }^{2}$, Magdalena Rudzińska ${ }^{3}$, \\ Anna Grygier $^{3}{ }^{(0)}$, Aleksander Siger ${ }^{3}{ }^{(D)}$, Katarzyna Cieślik-Boczula ${ }^{4}$, Sylwia Orczewska-Dudek ${ }^{1}$ \\ and Władysław Migdał ${ }^{5}$ (i)
}

1 Department of Animal Nutrition and Feed Sciences, National Research Institute of Animal Production, Krakowska Str. 1, 32-083 Balice, Poland; dorota.bederska@iz.edu.pl (D.B.-Ł.); sylwia.orczewska@iz.edu.pl (S.O.-D.)

2 Liposolutions Ltd., Gospodaercza Street 26, 20-213 Lublin, Poland; office@liposulutions.pl

3 Faculty of Food Science and Nutrition, Poznan University of Life Sciences, Wojska Polskiego 28, 60-637 Poznan, Poland; magdalena.rudzinska@up.poznan.pl (M.R.); anna.grygier@up.poznan.pl (A.G.); asiger@up.poznan.pl (A.S.)

4 Faculty of Chemistry, University of Wroclaw, ul. F. Joliot-Curie 14, 50-383 Wrocław, Poland; katarzyna.cieslik@chem.uni.wroc.pl

check for updates

Citation: Bederska-Łojewska, D.;

Pieszka, M.; Marzec, A.; Rudzińska,

M.; Grygier, A.; Siger, A.;

Cieślik-Boczula, K.;

Orczewska-Dudek, S.; Migdał, W.

Physicochemical Properties, Fatty

Acid Composition, Volatile

Compounds of Blueberries,

Cranberries, Raspberries, and

Cuckooflower Seeds Obtained Using

Sonication Method. Molecules 2021,

26,7446. https://doi.org/10.3390/

molecules 26247446

Academic Editor: Pierluigi Plastina

Received: 25 October 2021

Accepted: 23 November 2021

Published: 8 December 2021

Publisher's Note: MDPI stays neutral with regard to jurisdictional claims in published maps and institutional affiliations.

Copyright: (c) 2021 by the authors. Licensee MDPI, Basel, Switzerland. This article is an open access article distributed under the terms and conditions of the Creative Commons Attribution (CC BY) license (https:/ / creativecommons.org/licenses/by/ $4.0 /)$.
5 Department of Animal Product Technology, Balicka 122, 31-149 Kraków, Poland; wladyslaw.migdal@urk.edu.pl

* Correspondence: marek.pieszka@iz.edu.pl
Abstract: Every year, thousands of tons of fruit seeds are discarded as agro-industrial by-products around the world. Fruit seeds are an excellent source of oils, monounsaturated fatty acids, and n- 6 and n-3 polyunsaturated essential fatty acids. This study aimed to develop a novel technology for extracting active substances from selected seeds that were obtained after pressing fruit juices. The proposed technology involved sonification with the use of ethyl alcohol at a low extraction temperature. Seeds of four species-blueberry (Vaccinium myrtillus L.), raspberry (Rubus idaeus), cranberry (Vaccinium macrocarpon), and cuckooflower (Cardamine pratensis) -were used for extraction. Following alcohol evaporation under nitrogen, the antioxidant activity, chemical composition, and volatile compounds of the obtained extracts were analyzed using chromatographic methods, including gas chromatography (GC)-mass spectrometry (MS) (GC-MS/MS), and high-performance liquid chromatography-MS. We analyzed physicochemical properties, fatty acid, and volatile compounds composition, sterol and tocochromanol content of blueberry, cranberry, raspberry, and cuckooflower seed oils obtained by sonication. This method is safe and effective, and allows for obtaining valuable oils from the seeds.

Keywords: seed oils; fatty acids; tocopherols; tocotrienols; phytosterols

\section{Introduction}

Poland is a major fruit producer in the European Union. It ranks next to Spain, and outperforms France and Greece in fruit harvest. Fruit production is an important agricultural sector in the country. Fruit cultivation in Poland accounted for $13 \%$ of the overall crop production in 2019 (over 4 million PLN) and is on the rise, constituting approximately $10 \%$ of the total production volume of the European Union [1]. Seeds remaining after juice pressing are rich in valuable lipid compounds, and can therefore be considered as useful raw materials. Such seeds are characterized by high fat contents, and contain substances of high biological value. In addition, they are a valuable source of natural antioxidants (anthocyanins, polyphenols, flavonoids, vitamin E, beta-carotene, and xanthophylls), unsaturated fatty acids, mineral and aromatic compounds, antibacterial and antiviral substances, and 
so on [2]. As consumers prefer high-quality foods, there is a need to produce minimally processed food products, without the addition of chemical additives or synthetic vitamins. Supplementation with natural oils that are rich in the above-mentioned substances may improve the palatability and rheological properties of food products, as well as enhance their nutritional value. Among the lipid components in oils, triacylglycerols (TAGs; esters of glycerol and fatty acids) are the most important, followed by non-TAG groups of compounds such as phospholipids, sterols, tocopherols, and carotenoids, which are present in much smaller amounts [2,3]. These components determine the nutritional value of oils and influence their stability properties, especially oxidative stability. Seeds of berries, such as blueberries, cranberries, raspberries, and cuckooflower contain a high amount of PUFA. These acids are not synthesized in the human body, and hence must be supplied through food.

According to the recommendations of human nutrition specialists, the intake of total fats should be reduced. This can be achieved by increasing the intake of PUFA [4]. Apart from linoleic acid (LA) and long-chain polyunsaturated fatty acids (LC PUFA), $\alpha$ linolenic acid (ALA), belonging to the family of n-3 acids, is an important PUFA. Its content in the studied oils is as high as $30 \%$. A recent study reported that n-3 fatty acids have physiological and health-promoting properties, and are especially valuable in the prevention of cardiovascular diseases [5]. The health benefits of $\gamma$-linolenic acid (GLA) have also been reported, with a particular emphasis on the prevention of inflammatory and allergic diseases, and cardiovascular disorders [6].

Vegetable fatty acids, which belong to the group of essential unsaturated fatty acids (EUFA), are characterized by high biological activity. Seeds and oils derived from blueberries, cranberries, raspberries, and cuckooflowers contain the above-mentioned fatty acids, as well as antioxidant, anti-inflammatory, antiatherosclerotic, and anticancer substances, including tocochromanols, carotenoids, flavonoids, phytosterols, and phenolic acids [2,7]. Knowledge about the occurrence of antioxidants that can inhibit adverse changes in food and their activity and stability is important for technologists and nutritionists.

It is necessary to ensure that oils are properly protected after their extraction. Various measures taken for the protection of oils include the reduction or elimination of oxygen to avoid contact with oils, and preventing exposure to light and pro-oxidative metal ions (copper, iron). Furthermore, substances that can inhibit the oxidation process should be added to increase the shelf life of oils. Different antioxidants are used for this purpose; however, due to the health concerns associated with synthetic antioxidants, efforts are being made to significantly reduce the use of these substances, and replace them with natural or nature-identical antioxidants.

The versatile antioxidant activity of natural antioxidants may contribute to reducing the auto-oxidation of vegetable oils rich in triene-structured polyene fatty acids. When introduced into the diet, these antioxidants can scavenge free radicals, and may exert beneficial effects on the human body. With an aim of identifying novel sources of biologically valuable fats, this study developed a new method for extracting oils from blueberry, cranberry, raspberry, and cuckooflower seeds through sonification. The extracts were subjected to chemical and physicochemical analyses to investigate their composition and content of fatty acids, tocopherols, tocotrienols, phytosterols, and volatile compounds. The proposed method is completely safe, and does not require the use of harmful chemicals.

Berries, especially members of families such as Rosaceae (strawberries, raspberries, blackberries) and Ericaceae (blueberries, cranberries), are important dietary sources of bioactive compounds [8,9]. They have a delicious taste and pleasant aroma. Due to their antioxidant properties, they are economically valuable, and used as an ingredient in functional foods as recommended by nutritionists and food technologists. In the last decade, there has been intensified research on compounds that can protect the human body from free radicals and other active oxygen species. In particular, lipophilic components of plant oils exhibiting antioxidant activity and free radical-scavenging ability have been widely studied. So far, vegetable oils rich in 18-carbon triene-structured PUFA have been 
used as pharmaceutical preparations packaged in capsules. However, current oil extraction techniques, such as cold pressing in a nitrogen atmosphere and ultrasonographic extraction, allow for obtaining these oils in an almost unchanged state. Oils thus extracted are richer in biologically active compounds, with high nutritional value and antioxidant activity.

\section{Results and Discussion}

In this study, the peroxide number, which determines the amount of primary oxidation products, of the analyzed oils ranged from 7.39 to $8.78 \mathrm{meq} \mathrm{O}_{2} / \mathrm{kg}$. The permissible amount of peroxides in cold-pressed oils is much higher than that in refined oils $(<5$ meq $\mathrm{O}_{2} / \mathrm{kg}$ ) [10]. The peroxide value of the cold-pressed oils analyzed in the study did not exceed 10 meq $\mathrm{O}_{2} / \mathrm{kg}$, which is the value specified in the standards [10]. This suggests that the chemical composition of lipids (fatty acid composition, content of natural antioxidants and pro-oxidants) and therefore the susceptibility to environmental factors determine the oxidative changes occurring in natural, unrefined oils [11]. All the tested oils were characterized by low acid values (Table 1), which proves the low degree of hydrolysis and the small amount of free fatty acids. The acid values of oils reported in other studies were significantly higher. For instance, a study by Dimić et al. [11] showed that blackberry and raspberry oils had an acid value of $6.85-7.05$ and $17.18-17.86 \mathrm{mg} \mathrm{KOH} / \mathrm{g}$, respectively. Another study [12] presented acid values of 2.71-3.02, 2.60-3.45, and 2.72-3.73 mg KOH/g for cold-pressed strawberry seed oil, raspberry oil, and blackberry oil, which are similar to the values obtained in this study. The tested oils were products of good quality, not exceeding the prescribed norms, with the exception of acid value of raspberry oil, where the values were slightly above normal.

Table 1. Physicochemical properties of blueberry, cranberry, raspberry, cuckooflower seed oils obtained by sonification.

\begin{tabular}{ccccc}
\hline Characteristics & $\begin{array}{c}\text { Blueberry } \\
\text { Seed Oil }\end{array}$ & $\begin{array}{c}\text { Cranberry } \\
\text { Seed Oil }\end{array}$ & $\begin{array}{c}\text { Raspberry } \\
\text { Seed Oil }\end{array}$ & $\begin{array}{c}\text { Cuckooflower } \\
\text { Seed Oil }\end{array}$ \\
\hline Content of oil (\% dry matter) & $18.06 \pm 0.32$ & $14.52 \pm 0.31$ & $16.20 \pm 0.29$ & $20.32 \pm 0.28$ \\
Moisture content of seeds $(\%)$ & $8.46 \pm 0.11$ & $7.76 \pm 0.10$ & $7.82 \pm 0.11$ & $9.04 \pm 0.13$ \\
Acid value $\left(\mathrm{mg} \mathrm{KOH}_{\mathrm{K}} / \mathrm{g}\right)$ & $2.14 \pm 0.00$ & $1.78 \pm 0.00$ & $4.14 \pm 0.01$ & $1.38 \pm 0.00$ \\
Peroxide value $\left(\mathrm{meq} \mathrm{O}_{2} / \mathrm{kg}\right)$ & $8.78 \pm 0.02$ & $7.39 \pm 0.01$ & $8.45 \pm 0.03$ & $8.59 \pm 0.04$ \\
\hline
\end{tabular}

The chemical characteristics of cold-extracted blueberry, cranberry, raspberry, and cuckooflower native seed oils were evaluated to determine their fatty acid composition, positional distribution of fatty acids, and TAG profile. In addition, the effect of minor components, including tocopherols and pigments, on the oxidative stability of the studied oils was investigated. The results of a previous study by Li et al. [9] indicated that all the tested berry seed oils contained significant levels of palmitic acid (C16:0), stearic acid (C18:0), oleic acid (C18:1), LA (C18:2w-6), and ALA (C18:3w-3), along with a favorable ratio of $\omega-6 / \omega-3$ fatty acids (0.2-1.69). Moreover, palmitic acid, stearic acid, oleic acid, and ALA were predominantly distributed on the terminal positions [9]. In the present study, fatty acid analysis (Table 2) revealed a high content of 18:3n-3 acid in the analyzed oils as follows: cress-35.03\%, raspberry-31.1\%, blueberry-28.99\%, and cranberry-34.91\%. C 18:1 was detected as the predominant species in the tested berry seed oils: cress-28.24\%, raspberry-10.99\%, blueberry-21.02\%, and cranberry-20.23\%.

Vegetable oils with a low $n-6 / n-3$ acid ratio are especially beneficial to human nutrition. Blueberry, cranberry, raspberry, and cuckooflower oils have an $n-3 / n-6$ ratio of $1-2$. These oils can be included in the diets of people who are recalcitrant following heart attacks or cardiac surgeries. 
Table 2. Fatty acid composition of blueberry, cranberry, raspberry and cuckooflower seed oils obtained by sonification (\%).

\begin{tabular}{ccccc}
\hline Fatty Acids & Blueberry Seed Oil & Cranberry Seed Oil & Raspberry Seed Oil & Cuckooflower Seed Oil \\
\hline C14:0 & 0 & 0 & 0 & $0.07 \pm 0.00$ \\
C16:0 & $4.57 \pm 0.10$ & $5.32 \pm 0.08$ & $2.31 \pm 0.12$ & $7.09 \pm 0.10$ \\
C16:1 & $0.06 \pm 0.00$ & 0 & 0 & $0.09 \pm 0.00$ \\
C18:0 & $1.45 \pm 0.06$ & $0.87 \pm 0.03$ & $0.76 \pm 0.03$ & $2.41 \pm 0.05$ \\
C18:1 & $21.02 \pm 0.48$ & $20.23 \pm 0.44$ & $10.99 \pm 0.22$ & $7.24 \pm 0.36$ \\
C18:2n-6 & $43.33 \pm 0.74$ & $37.43 \pm 0.62$ & $52.59 \pm 0.89$ & 0.06 \\
C20:0 & $0.14 \pm 0.00$ & 0 & $0.26 \pm 0.01$ & $0.12 \pm 0.01$ \\
C18:3 n-6 & $0.08 \pm 0.00$ & 0 & 0 & $12.5 \pm 0.19$ \\
C20:1 & $0.13 \pm 0.00$ & $0.15 \pm 0.00$ & 0 & $35.03 \pm 0.68$ \\
C18:3 n-3 & $28.99 \pm 0.52$ & $34.91 \pm 0.59$ & $31.1 \pm 0.45$ & $4.57 \pm 0.15$ \\
C22: & 0 & 0 & 0 & 0 \\
C20:4 n-6 & $1.08 \pm 0.08$ & $1.08 \pm 0.08$ & 0 & \\
\hline
\end{tabular}

Seed oils from berries such as blueberries, raspberries, and cranberries are a rich source of PUFA. These acids are not synthesized in the human body, due to the lack of enzymes required for forming double bonds in the fatty acid chain at a position beyond C-9. In the human body, n-3 and n-6 fatty acids are part of cell membrane phospholipids, and their proportion in tissues mainly depends on the dietary supply. These are also a source of components that are used in the synthesis of biologically active compounds such as prostaglandins. Essential fatty acids are one of the major building blocks of cells, and are known to exhibit antiarrhythmic [13], anticoagulant [14], antiatherosclerotic [15], and anti-inflammatory [13] effects, and improve vascular endothelial function [15].

In addition to fatty acids, oils from blueberry, cranberry, raspberry, and cuckooflower seeds contain a number of antioxidant, anti-inflammatory, antiatherosclerotic, and anticancerous substances, including tocochromanols, carotenoids, flavonoids, phytosterols, and phenolic acids $[2,5,7,16-18]$. Plant fatty acids, which belong to a group of EUFA, are characterized by high biological activity. Phytosterols are an intriguing group of lipidlike compounds. Among them, $\beta$-sitosterol, campesterol, stigmasterol, brassicasterol, $\Delta 5$-avenasterol, $\Delta 7$-stigmasterol, and $\Delta 7$-avenasterol have been reported as important plant oil sterols $[19,20]$. In most vegetable oils, sterols are the main unsaponifiables. The average content of these compounds in vegetable oils ranges from 400 to $800 \mathrm{mg} / 100 \mathrm{~g}$, but there can be significant differences in the content in some oils [3,21].

As shown in Table 3, cuckooflower is an excellent source of phytosterols $(0.71 \mathrm{mg} / \mathrm{g}$ campesterol, $0.27 \mathrm{mg} / \mathrm{g}$ campestanol, $0.10 \mathrm{mg} / \mathrm{g}$ stigmasterol, $0.13 \mathrm{mg} / \mathrm{kg}$ brassicasterol, and $1.58 \mathrm{mg} / \mathrm{g} \beta$-sitosterol). The combined phytosterol content of cress oil was estimated at $14.41 \mathrm{mg} / \mathrm{g}$, which exceeds the typical range of $1-5 \mathrm{mg} / \mathrm{g}$ observed in most vegetable oils [22]. Crude commodity vegetable oils found with high phytosterol content were corn (8-22 mg/g) and rapeseed (5-11 mg/g) oils [22]. On the other hand, raspberry, blueberry, and cranberry extracts contained less amount of phytosterols, which include $\beta$-sitosterol $(2.01,1.45$, and $1.47 \mathrm{mg} / \mathrm{g}$, respectively) and campesterol (at $0.06-0.10 \mathrm{mg} / \mathrm{g}$ ).

Johansson et al. [23] found similar phytosterol content in the seeds of wild fruits from Finnish forests. Sitosterol is an important phytosterol that promotes the slow absorption of cholesterol, and thus allows maintaining low levels of total cholesterol in the peripheral blood. Unlike cholesterol, phytosterols exert some positive effects on the human body. They bind bile acids, and reduce total blood cholesterol without affecting the level of high-density lipoprotein cholesterol [24]. Phytosterols have also been reported to inhibit intestinal cancer. They are characterized by anticancer, antioxidant, and cholesterol-reducing properties [17]. In the present study, the content of tocopherols determined in the tested extracts varied widely. The highest amount of tocopherols was found in raspberry $(223.49 \mathrm{mg} / 100 \mathrm{~g})$, followed by $\gamma$-tocopherol $(130.38 \mathrm{mg} / 100 \mathrm{~g})$, and $\alpha$-tocopherol $(75.32 \mathrm{mg} / 100 \mathrm{~g})$. Cress contained a high amount of tocopherols (112. $44 \mathrm{mg} / 100 \mathrm{~g}$ ), with $\gamma$-tocopherol and $\alpha$ tocopherol estimated at 107.94 and $1.09 \mathrm{mg} / 100 \mathrm{~g}$, respectively. The level of vitamin $\mathrm{E}$ in blueberry was $4.84 \mathrm{mg} / 100 \mathrm{~g}$, whereas in cranberries, it was only $1.65 \mathrm{mg} / 100 \mathrm{~g}$. 
Table 3. Sterols content of oils from of blueberry, cranberry, raspberry and cuckooflower seed oils obtained by sonification $(\mathrm{mg} / \mathrm{g})$.

\begin{tabular}{|c|c|c|c|c|}
\hline Phytosterols & Blueberry Seed Oil & $\begin{array}{c}\text { Cranberry Seed } \\
\text { Oil }\end{array}$ & Raspberry Seed Oil & $\begin{array}{c}\text { Cuckooflower Seed } \\
\text { Oil }\end{array}$ \\
\hline Cholesterol & 0 & 0 & 0 & $0.19 \pm 0.01$ \\
\hline Brassicasterol & 0 & 0 & 0 & $0.12 \pm 0.02$ \\
\hline Campesterol & $0.08 \pm 0.01$ & $0.08 \pm 0.03$ & $0.11 \pm 0.00$ & $0.66 \pm 0.06$ \\
\hline Campestanol & 0 & 0 & 0 & $0.25 \pm 0.03$ \\
\hline Stigmasterol & 0 & $0.03 \pm 0.01$ & $0.06 \pm 0.02$ & $0.08 \pm 0.03$ \\
\hline$\beta$-Sitosterol & $1.38 \pm 0.09$ & $1.51 \pm 0.05$ & $1.89 \pm 0.18$ & $1.48 \pm 0.14$ \\
\hline Sitostanol & $0.04 \pm 0.00$ & $0.04 \pm 0.00$ & $0.08 \pm 0.03$ & $0.01 \pm 0.00$ \\
\hline$\Delta 5$-Avenasterol & $0.03 \pm 0.01$ & 0 & $0.06 \pm 0.00$ & $0.60 \pm 0.06$ \\
\hline Lanosadienol & $0.07 \pm 0.01$ & 0 & 0 & 0 \\
\hline$\alpha$-amyrin & 0 & $0.03 \pm 0.00$ & 0 & 0 \\
\hline$\Delta 7$-Stigmasterol & $0.05 \pm 0.01$ & $0.39 \pm 0.02$ & $0.06 \pm 0.01$ & 0 \\
\hline Stigmasta- $(8,24)$-dien- $3 \beta$-ol & $0.17 \pm 0.01$ & 0 & 0 & 0 \\
\hline Cycloartenol & $0.06 \pm 0.01$ & 0 & $0.10 \pm 0.02$ & 0 \\
\hline$\Delta 7$-Avenasterol & 0 & 0 & $0.07 \pm 0.00$ & 0 \\
\hline 24-methylenecycloartenol & $0.08 \pm 0.02$ & $0.07 \pm 0.00$ & $0.23 \pm 0.03$ & 0 \\
\hline Citrostadienol & 0 & 0 & $0.07 \pm 0.01$ & 0 \\
\hline Total content & 3460.0 & 6824.9 & 4643.1 & 5384.1 \\
\hline
\end{tabular}

Compared to the results of a previous study by Omah et al. [25], a higher concentration of tocopherols was noted in the obtained raspberry oil, while the tocopherol profile was similar, with the $\gamma$ isomer found to be dominant (Table 4). The tocopherol content of cranberry, raspberry, blueberry, and cress seed oils was higher compared to commercial tocopherolrich oils, such as corn and soybean oil (162 and $180 \mathrm{mg} / 100 \mathrm{~g}$ oil, respectively) [26]. The method of extraction can influence the tocopherol content in oils. The refining process can reduce the content of tocopherols by up to $40 \%$. A study on the oxidative stability of oils [27] indicated that it is difficult to stabilize vegetable oils by adding tocopherols, as native tocopherols in these oils are at the optimal levels needed for stabilization.

Table 4. Tocochromanols content of blueberry, cranberry, raspberry and cuckooflower seed oils obtained by sonification (mg/100 g).

\begin{tabular}{|c|c|c|c|c|}
\hline Tocochromanols & Blueberry Seed Oil & Cranberry Seed Oil & Raspberry Seed Oil & Cuckooflower Seed Oil \\
\hline $\begin{array}{c}\text { Tocopherols }(\mathrm{mg} / 100 \mathrm{~g}) \text { : } \\
\alpha \text {-tocopherol }\end{array}$ & $0.06+0.01$ & $0.09+0.01$ & $75.32+0.42$ & $1.08+0.15$ \\
\hline$\beta$-tocopherol & $\begin{array}{c}0.06 \pm 0.01 \\
\text { nd }\end{array}$ & $\begin{array}{l}0.09 \pm 0.01 \\
\text { nd }\end{array}$ & $\begin{array}{c}75.32 \pm 0.42 \\
\text { nd }\end{array}$ & $\begin{array}{c}1.08 \pm 0.15 \\
\text { nd }\end{array}$ \\
\hline$\gamma$-tocopherol & $0.39 \pm 0.01$ & $0.12 \pm 0.02$ & $130.38 \pm 0.39$ & $107.94 \pm 0.41$ \\
\hline$\delta$-tocopherol & $0.13 \pm 0.02$ & $0.06 \pm 0.06$ & $18.41 \pm 4.6$ & $3.41 \pm 0.24$ \\
\hline $\begin{array}{c}\text { Tocotrienols }(\mathrm{mg} / 100 \mathrm{~g}) \text { : } \\
\alpha \text {-tocotrienol }\end{array}$ & $0.07 \pm 0.01$ & $0.11 \pm 0.01$ & $2.08 \pm 0.06$ & nd \\
\hline$\beta$-tocotrienol & nd & $0.14 \pm 0.01$ & $1.38 \pm 0.13$ & nd \\
\hline$\gamma$-tocotrienol & $2.68 \pm 0.05$ & $0.55 \pm 0.01$ & $0.33 \pm 0.01$ & nd \\
\hline$\delta$-tocotrienol & nd & $0.60 \pm 0.01$ & nd & nd \\
\hline Plastochromanol-8 & 0 & 0 & 0 & $4.00 \pm 0.06$ \\
\hline Sum of tocols $(\mathrm{mg} / 100 \mathrm{~g})$ & $4.85 \pm 0.11$ & $1.65 \pm 0.01$ & $223.49 \pm 0.96$ & $112.44 \pm 0.80$ \\
\hline
\end{tabular}

nd (not detected) - limit of quantitative for each tocol is $0.5 \mathrm{mg} / 100 \mathrm{~g}$.

The analysis of volatile odorous compounds revealed that their content was high, and varied depending on the studied plant. In cress, a total of 140 compounds were identified, with dimethyl sulfoxide, 2-butenal, and 2-pentenal found to be dominant. In raspberry, a total of 137 volatile compounds were identified, with hexanal, ethyl acetate, butanoic ethyl ester, 3-hexen-1-ol, and acetate dominant. In blueberry, 173 volatile compounds 
were identified, of which hexanal, pentanal, cyclopropane 1,1-dimethyl-, benzaldehyde, 5hepten-2-one, and 6-methyl- were dominant. Cranberry contained 133 volatile compounds, of which 1,2-dimethyl cyclopropane, 1,3,5,7-cyclooctatetraene, 2,4-heptadienal, 2-butenal, 2-heptenal, 2-pentenal, furan, 2-ethyl-, and hexanal were found at high concentrations.

Tables 5-8 present the results of the analysis of the most important volatile compounds in the studied oils, whose percentage was above $1 \%$. Among the tested oils, the highest amount of volatile compounds was found in cress oil $(30 \%)$, cranberry oil $(22 \%)$, and raspberry and blueberry oil (19\%). The main chemical groups represented by the compounds identified were esters, aldehydes, ketones, acids, and terpenes. The high content of esterified volatile aromatic compounds contributes to the fruity characteristic, taste, and aroma of raspberry and cranberry oils. Many of the identified aromatic compounds are characterized by a strong olfactory property, and enhance the characteristic aroma of berries with their spicy, floral, and fruity flavors. This suggests that the aroma of vegetable oils is rendered by the volatile compounds present in the plant materials, such as short-chain fatty acids, heterocyclic compounds, ketones, alcohols, esters, and aldehydes, or results from the processing or storage of the materials [28].

Table 5. Percentage composition of volatile compounds from blueberry seed oil obtained by sonification.

\begin{tabular}{|c|c|c|c|c|}
\hline Item & RT & Area \% & Odor Description & References \\
\hline 3-Methyl-1,4-heptadiene & 725 & $1.09 \pm 0.07$ & & \\
\hline 1H-1,2,3-Triazole & & $1.08 \pm 0.06$ & & \\
\hline 2,4-Heptadienal, (E,E)- & 999 & $1.04 \pm 0.10$ & fatty, rancid & [29] \\
\hline 2-Heptenal, (Z)- & 960 & $1.25 \pm 0.11$ & oxidized, tallowy, pungent & [30] \\
\hline 2-Octene & 817 & $1.19 \pm 0.10$ & & \\
\hline 2-Pentenal, (E)- & 353 & $1.14 \pm 0.04$ & fruity aroma & [31] \\
\hline Acetic acid & 609 & $1.53 \pm 0.13$ & sour vinegary & [29] \\
\hline Acetic acid, anhydride with formic acid & 645 & $1.20 \pm 0.09$ & & \\
\hline Acetic acid, methyl ester & 513 & $2.17 \pm 0.15$ & ethereal, sweet & [29] \\
\hline Benzaldehyde & & $1.69 \pm 0.14$ & bitter almonds, penetrating & [29] \\
\hline 2-Nitrobutane & & $1.20 \pm 0.08$ & & \\
\hline 1,1-Dimethylcyclopropane & 460 & $2.46 \pm 0.18$ & & \\
\hline Ethyl Acetate & 610 & $4.26 \pm 0.30$ & sticky, sweet & {$[30]$} \\
\hline Hexanal & 801 & $2.05 \pm 0.15$ & grassy, fatty & [29] \\
\hline Hexane & 600 & $3.81 \pm 0.15$ & petroleum-like & [32] \\
\hline Methacrolein & 568 & $3.95 \pm 0.28$ & smell of ozone & [33] \\
\hline Trimethylene oxide & & $1.71 \pm 0.15$ & agreeable aromatic & [34] \\
\hline
\end{tabular}

Table 6. Percentage composition of volatile compounds from raspberry seed oil obtained by sonification.

\begin{tabular}{|c|c|c|c|c|}
\hline Item & RT & Area \% & Odor Description & References \\
\hline 3,5-Heptatriene, (E,E)- & & $2.19 \pm 0.09$ & & \\
\hline 1,6-Heptadien-4-ol & 876 & $0.66 \pm 0.05$ & & \\
\hline 3-Methyl-1 butanol & 736 & $2.51 \pm 0.22$ & woody, whiskey, sweet & [29] \\
\hline 3-Methyl-1-butanol, acetate & 878 & $1.13 \pm 0.10$ & banana & {$[35]$} \\
\hline 2-Methyl-1-propanol & 622 & $1.94 \pm 0.14$ & wine, penetrating & [29] \\
\hline 2-Hexenal, (E)- & 854 & $1.02 \pm 0.07$ & green leaf, apple-like & [29] \\
\hline 3-Methyl-3-Buten-1-ol & 734 & $1.30 \pm 0.09$ & fresh, fruity, green, slight lavender & [36] \\
\hline 3-Hexen-1-ol, acetate, (Z)- & 1009 & $1.05 \pm 0.07$ & & \\
\hline Acetic acid & 609 & $2.17 \pm 0.16$ & sour vinegary & [29] \\
\hline Acetic acid, methyl ester & 513 & $1.08 \pm 0.06$ & ethereal, sweet & [29] \\
\hline Benzene & & $1.25 \pm 0.08$ & petroleum-like & [37] \\
\hline Ethanol & & $1.60 \pm 0.07$ & alcohol & [30] \\
\hline Ethyl Acetate & & $8.78 \pm 0.52$ & fruity & [38] \\
\hline Hexanal & 801 & $2.48 \pm 0.21$ & grassy, fatty & [29] \\
\hline 2,2-Dimethylpropanal & 110 & $3.14 \pm 0.29$ & & \\
\hline Propylene oxide & & $1.20 \pm 0.08$ & ethereal & [39] \\
\hline p-Xylene & & $1.22 \pm 0.09$ & sweet & [40] \\
\hline
\end{tabular}


Table 7. Percentage composition of volatile compounds from cranberry seed oil obtained by sonification Percentage composition of volatile compounds from cranberry seed oil obtained by sonification.

\begin{tabular}{|c|c|c|c|c|}
\hline Item & RT & Area \% & Odor Description & References \\
\hline 1,2-Dimethyl cyclopropene & 539 & $1.11 \pm 0.10$ & & \\
\hline 1,3,5,7-Cyclooctatetraene & 850 & $1.19 \pm 0.10$ & & \\
\hline 1-Penten-3-one & 684 & $1.08 \pm 0.09$ & green, pungent & [29] \\
\hline 2,4-Heptadienal, (E,E)- & 999 & $2.27 \pm 0.18$ & fatty, rancid & \\
\hline 2-Butenal, (E)- & 649 & $2.43 \pm 0.21$ & flower & [29] \\
\hline 2-Heptenal, (Z)- & 964 & $1.13 \pm 0.08$ & oxidized, tallowy, pungent & [30] \\
\hline 2-Hexenal & 854 & $1.18 \pm 0.07$ & green leaf, apple-like & [29] \\
\hline 2-Penten-1-ol, (E)- & 510 & $1.87 \pm 0.08$ & & \\
\hline 2-Pentenal, (E)- & 751 & $1.78 \pm 0.11$ & fruity aroma & [31] \\
\hline 2-Pentene, (E)- & 501 & $1.65 \pm 0.14$ & & \\
\hline 4-Heptenal, (Z)- & 888 & $1.07 \pm 0.05$ & & \\
\hline Acetic acid & 609 & $3.02 \pm 0.24$ & sour, vinegary & [29] \\
\hline Ethyl Acetate & & $3.27 \pm 0.21$ & fruity & [38] \\
\hline 2-Ethylfuran & 739 & $1.49 \pm 0.06$ & sweet, etheral & [29] \\
\hline Furfural & 830 & $2.48 \pm 0.22$ & & \\
\hline Hexanal & 801 & $2.31 \pm 0.20$ & grassy, fatty & [29] \\
\hline Hexane & 600 & $4.50 \pm 0.36$ & petroleum-like & [32] \\
\hline Oxirane, methyl-, (S)- & & $1.44 \pm 0.12$ & sweet, alcoholic & [41] \\
\hline Pentanal & 714 & $1.27 \pm 0.08$ & woody, bitter, oily & [29] \\
\hline Trimethylene oxide & & $1.34 \pm 0.10$ & & \\
\hline
\end{tabular}

Table 8. Percentage composition of volatile compounds from cuckooflower seed oil obtained by sonification.

\begin{tabular}{|c|c|c|c|c|}
\hline Item & RT & Area \% & Odor Description & References \\
\hline 3-Methyl-1 butanol & 736 & $2.09 \pm 0.12$ & disagreeable & \\
\hline 3-Methyl-1 butanol, acetate & 867 & $1.03 \pm 0.09$ & banana & [35] \\
\hline 1-Hexanol & 872 & $1.04 \pm 0.08$ & fruit, soft & [29] \\
\hline 1-Octanol & 1078 & $1.29 \pm 0.08$ & penetrating, aromatic & [42] \\
\hline 1-Penten-3-one & 683 & $1.72 \pm 0.12$ & green, pungent & [29] \\
\hline 2-Methyl-1-propanol & 654 & $2.30 \pm 0.13$ & Wine, penetrating & [29] \\
\hline 2,4-Heptadienal, (E,E)- & 999 & $2.05 \pm 0.18$ & fatty, rancid & [29] \\
\hline 2-Butenal, (E)- & 648 & $4.79 \pm 0.33$ & flower & [29] \\
\hline 2-Ethyl-trans-2-butenal & 856 & $1.69 \pm 0.13$ & & \\
\hline 2-Heptanone & 889 & $1.12 \pm 0.10$ & sweet, fruity & [29] \\
\hline 2-Heptenal, (Z)- & 964 & $1.70 \pm 0.15$ & oxidized, tallowy, pungent & [30] \\
\hline 2-Hexenal & 855 & $1.11 \pm 0.09$ & green leaf, apple-like & [29] \\
\hline 2-Pentenal, (E)- & 383 & $1.30 \pm 0.80$ & fruity aroma & [31] \\
\hline 6-Methyl-5-hepten-2-one & 988 & $1.42 \pm 0.13$ & oily, pungent & [29] \\
\hline Acetic acid, methyl ester & 513 & $1.23 \pm 0.01$ & ethereal, sweet & [29] \\
\hline Acetonitrile & & $1.24 \pm 0.11$ & sweet, ethereal & [43] \\
\hline Carbon dioxide & & $1.11 \pm 0.09$ & no odor & {$[44]$} \\
\hline Ethyl Acetate & 610 & $4.63 \pm 0.32$ & fruity & [38] \\
\hline Furan, 2-ethyl- & 720 & $1.18 \pm 0.08$ & smoky, burnt & {$[45]$} \\
\hline Furfural & 830 & $1.14 \pm 0.09$ & & \\
\hline 5-Ethyl-2,2,3-trimethylheptan & & $1.19 \pm 0.10$ & & \\
\hline Hexanal & 802 & $2.67 \pm 0.22$ & grassy, fatty & [27] \\
\hline Fluorotrinitromethane & & $1.10 \pm 0.08$ & & \\
\hline 3,3-Dimethyloxetane & & $1.11 \pm 0.11$ & & \\
\hline Pentanal & 699 & $1.41 \pm 0.14$ & woody, bitter, oily & [29] \\
\hline Trimethylene oxide & & $1.79 \pm 0.12$ & agreeable aromatic & {$[34]$} \\
\hline p-Xylene & & $1.09 \pm 0.01$ & sweet & [40] \\
\hline
\end{tabular}


In cold-pressed oils, most chemical changes occur during storage and are related to the oxidation of unsaturated fatty acids [46]. Therefore, it is recommended that coldpressed oils should be consumed within 6-12 months of production. Oil deterioration is mainly associated with volatile compounds such as aldehydes, ketones, esters, and furan derivatives, which are formed as a result of lipid oxidation processes [47,48], especially the auto-oxidation of unsaturated fatty acids. Several compounds, including hexanal or nonanal, are used as markers to detect the oxidation of lipids [49,50].

The above results highlight that fruit seeds and their oils obtained as agricultural byproducts are promising sources of valuable lipid compounds. The seeds are characterized by high oil content, beneficial lipid composition, and high biological activity, as well as potential biotechnological, nutritional, and pharmaceutical applications.

\section{Materials and Methods}

\subsection{Materials and Extraction of Fat from the Seeds}

\subsubsection{Sample Preparation}

Blueberry, cranberry, raspberry, and cuckooflower seeds were procured from Polfeed in 2020 (Skrzyńsko, Poland), which specializes in the drying and packaging of fruit pomace resulting from the extraction of fruit and vegetable juices. Pomace with a moisture content of approximately 55\% was obtained from Hortex (Skrzyńsko, Poland)), and dried on drum driers to reduce the moisture to $<10 \%$. The dried pomace was then cut and ground, and the seeds were separated. The production line (Scorpion, Poland), which included a chopper, a separator, and a pneumatic tunnel, was used to separate seeds from other parts. Before extraction, the seeds were ground in a Fritsch PULVERISETTE 25 laboratory mill (Fritsch, Kastl, Germany) with a mesh diameter of $1 \times 1 \mathrm{~mm}$.

\subsubsection{Extraction Procedures}

The extracts from blueberry, cranberry, raspberry, cuckooflower seeds were obtained from the ground material by sonication. The extraction conditions involved the grinding of the seed samples, followed by pre-extraction with $70 \%$ ethanol at a temperature of $-60{ }^{\circ} \mathrm{C}$ for $30 \mathrm{~min}$. After this time as the extraction mixture reached $-30{ }^{\circ} \mathrm{C}$ the sonification process was started. Since the temperature increased during the sonication process, the vessel with the extraction mixture was placed in ice. A low extraction temperature was used, following previous studies, where it was found that the optimum range for extraction of substances from stone fruit seeds is between $-30{ }^{\circ} \mathrm{C}$ and $-20^{\circ} \mathrm{C}$. The solution was extracted on a Hielscher Ultrasonics UP200ht sonifier (Hielscher, Teltow, Germany) for 15 min under the following conditions: $30 \mathrm{Ws} / \mathrm{mL}$ and $90 \mu \mathrm{m}$. After the alcoholic extracts were obtained, the solvent was evaporated under nitrogen at $30^{\circ} \mathrm{C}$. The oil layer was collected from the surface, placed in sealed dark glass tubes under nitrogen, and stored in a refrigerator at $4^{\circ} \mathrm{C}$ until analysis.

\subsection{Fatty Acid Composition}

The fatty acid composition of the oils was determined by the gas chromatography flame-ionization detection (GC-FID) technique. Fatty acid methyl esters (FAME) were obtained [51] and subjected to GC-FID using a Hewlett-Packard 5890 II (Agilent Technologies, Poway, CA, USA) gas chromatograph equipped with a Supelcowax-10 capillary column $(30 \mathrm{~m} \times 0.25 \mathrm{~mm} \times 0.25 \mu \mathrm{m})$. The initial oven temperature was set at $60^{\circ} \mathrm{C}$, which was then increased to $12{ }^{\circ} \mathrm{C} / \mathrm{min}$ to $200{ }^{\circ} \mathrm{C}$, and held for $25 \mathrm{~min}$. The injector and detector were maintained at a temperature of $240^{\circ} \mathrm{C}$. The separated FAME were identified by comparing with the retention data of standards. Analyses were performed in three replicates.

\subsection{Volatile Compounds}

The volatile compounds of oils were extracted using a 2-cm CAR/DVB/PDMS fiber (Supelco, Bellefonte, PA) [52]. Samples were in a heater block set on $50{ }^{\circ} \mathrm{C}$ for $5 \mathrm{~min}$. Then, the SPME fibre was exposed to a headspace of the sample for $30 \mathrm{~min}$. Next, the SPME 
fiber was desorbed into the GC injection port at $250{ }^{\circ} \mathrm{C}$. Compounds were identified using an Agilent Technologies 6890N GC $\times$ GC-ToF MS system (Agilent Technologies, Palo Alto, CA) coupled to PEGASUS 4 time-of-flight mass spectrometer (LECO, St. Joseph, MI, USA). Separation was performed using two capillary columns: a nonpolar DB-5 column (30 m $\times$ $250 \mathrm{~mm} \times 0.5 \mathrm{~mm})$ as the first dimension, and a polar Supelcowax-10 column $(0.75 \mathrm{~m} \times$ $100 \mathrm{~mm} \times 0.1 \mathrm{~mm}$ ) as the second dimension. The oven initial temperature was $40^{\circ} \mathrm{C}$, and it was held for $3 \mathrm{~min}$. Then, the temperature increased at $4{ }^{\circ} \mathrm{C} / \mathrm{min}$ to $160^{\circ} \mathrm{C}$. After that, the temperature increased at $10{ }^{\circ} \mathrm{C} / \mathrm{min}$ to $280^{\circ} \mathrm{C}$, and it was held for $3 \mathrm{~min}$. An electron impact mode was $70 \mathrm{eV}$, and masses were scanned from 33 to $333 \mathrm{Da}$. Data were collected and processed using LECO Chroma-TOF v.4.40.

\subsection{Tocopherols}

The qualitative and quantitative determination of tocopherols were carried out using a Waters HPLC system (Waters, Milford, MA, USA), consisting of a pump (Waters 600), a fluorimetric detector (Waters 474), a photodiode array detector (Waters 2998 PDA), an autosampler (Waters 2707), a column oven (Waters Jetstream 2 Plus), and a LiChrosorb Si 60 column $(250 \times 4.6 \mathrm{~mm} \times 5 \mu \mathrm{m})$ from Merck (Darmstadt, Germany). A mixture of n-hexane and 1,4-dioxane $(96: 4, v / v)$ was used as the mobile phase at a flow rate of 1.0 $\mathrm{mL} / \mathrm{min}$. The fluorescence of tocochromanols was detected at an excitation wavelength of $295 \mathrm{~nm}$ and an emission wavelength of $330 \mathrm{~nm}$ [53].

\subsection{Sterols}

The content of sterols was determined by GC following a previously described procedure [54]. Briefly, lipids (0.05 g) were saponified with $1 \mathrm{M} \mathrm{KOH}$ in methanol, and the unsaponifiables were extracted using a mixture of hexane and methyl tert-butyl ether $(1: 1, v / v)$. The solvent was evaporated under a nitrogen stream, and dry residues were dissolved in anhydrous pyridine, and silylated with BSTFA + 1\% TMCS (Supelco, Bellefonte, PA). The sterol derivatives were separated on an Agilent Technologies 6890 Plus GC (Agilent Technologies. Palo Alto. CA, USA) system equipped with a flame-ionization detector and a DB-35MS capillary column $(25 \mathrm{~m} \times 0.20 \mathrm{~mm}, 0.33 \mu \mathrm{m}$; Agilent J\&W, USA). Samples were injected in splitless mode. The column temperature was initially set at $100^{\circ} \mathrm{C}$ and held for $5 \mathrm{~min}$, then increased to $250^{\circ} \mathrm{C}$ at $25^{\circ} \mathrm{C} / \mathrm{min}$ and held for $1 \mathrm{~min}$, and further increased to $290^{\circ} \mathrm{C}$ at $3{ }^{\circ} \mathrm{C} / \mathrm{min}$ and held for $20 \mathrm{~min}$. The detector was set at a temperature of $300{ }^{\circ} \mathrm{C}$. Hydrogen was used as the carrier gas at a flow rate of $1.5 \mathrm{~mL} / \mathrm{min} .5 \alpha$-Cholestane was used as an internal standard. Identification was performed by comparing the retention data of compounds with the standards. Samples of each oil were analyzed in triplicate.

\subsection{Acid Value}

The acid value was calculated as the milligrams of potassium hydroxide needed to neutralize the free fatty acids in $1 \mathrm{~g}$ of the sample [55].

\subsection{Peroxide Value}

The peroxide value was determined as described by AOCS [56].

\subsection{Statistical Analysis}

The analysis of the chemical composition, bioactive compound content, and physicochemical properties of the oils was performed in three replications. The results were expressed as mean and standard deviation.

\section{Conclusions}

To sum up, the oils obtained from blueberry, cranberry, raspberry, and cress seeds by sonification had a favorable fatty acid composition, and significant amounts of tocopherols and phenolic compounds. Due to the high availability of pomace from fruit processing, there is a growing interest in oil sourcing by different companies. The measured parameters 
(physicochemical properties, fatty acid and volatile compounds composition, and sterols and tocochromanols content) of oils are within a normal range. It shows that sonification is a new efficient technology that can not only be used safely and is environmentally friendly, but is also effective and economical.

Author Contributions: Data curation, M.P. and M.R.; Methodology, M.R., A.G. and A.S.; Writingoriginal draft, D.B.-Ł., M.P., A.M. and M.R.; Writing-review \& editing, D.B.-Ł., M.P., A.M., M.R., A.G., A.S., K.C.-B., S.O.-D. and W.M. All authors have read and agreed to the published version of the manuscript.

Funding: This research received no external funding.

Institutional Review Board Statement: Not applicable.

Informed Consent Statement: Not applicable.

Data Availability Statement: Repository of Centre for Open Science.

Conflicts of Interest: The authors declare no conflict of interest.

\section{References}

1. Główny Urząd Statystyczny. Quality of Life in Poland; Central Statistical Office: Poland, Warsaw, 2018.

2. Alves, E.; Simoes, A.; Rosário Domingues, M. Fruit seeds and their oils as promising sources of value-added lipids from agro-industrial byproducts: Oil content, lipid composition, lipid analysis, biological activity and potential biotechnological applications. Crit. Rev. Food Scie. Nutr. 2021, 61, 1305-1339. [CrossRef] [PubMed]

3. Shahidi, F.; Shukla, V.K.S. Nontriacylglycerol constituents of fats, oils. Inform-International News on Fats Oils and Related Materials. J. Jpn. Oil Chem. Soc. 1996, 7, 1227-1231.

4. Jarosz, M.; Rychlik, E.; Stoś, K.; Charzewska, J. Nutrition Standards for the Polish Population Nutrition standards for the Polish population. In Collective Work under the Red. Miroslawa Jarosz; Wyd Food and Nutrition Institute: Poland, Warsaw, 2017 ; pp. 1-372.

5. Filion, K.B.; Khoury, F.E.; Bielinski, F.; Schiller, I.; Dendukuri, N.; Bromphy, J.M. Omega-3 fatty acids in high-risk cardiovascular patients: A meta-analysis of randomized controlled trials. BMC Cardiovasc. Disord. 2010, 10, 24. [CrossRef] [PubMed]

6. Rakesh, K.; Yung-Sheng, H. Gamma linolenic acid: An antiinflammatory omega-6 fatty acid. Curr. Pharmac. Biotech. 2006, 7, 531-534.

7. Skrovankova, S.; Sumczynski, D.; Mlcek, J.; Jurikova, T.; Sochor, J. Bioactive Compounds and Antioxidant Activity in Different Types of Berries. Int. J. Mol. Sci. 2015, 16, 24673-24706. [CrossRef] [PubMed]

8. Parry, J.; Su, L.; Moore, J.; Cheng, Z.; Luther, M.; Rao, J.N.; Wang, J.-Y.; Yu, L.L. Chemical Compositions, Antioxidant Capacities, and Antiproliferative Activities of Selected Fruit Seed Flours. J. Agric. Food Chem. 2006, 54, 3773-3778. [CrossRef] [PubMed]

9. Li, Q.; Wang, J.; Shahidi, F. Chemical Characteristics of Cold-Pressed Blackberry, Black Raspberry, and Blueberry Seed Oils and the Role of the Minor Components in Their Oxidative Stability. J. Agric. Food Chem. 2016, 64, 5410-5416. [CrossRef] [PubMed]

10. Wroniak, M.D.Ł. Evaluation of oxidative stability of selected cold pressed edible oils. Oilseeds Crops 2007, 28, 303-317.

11. Dimić, E.B.; Vujasinović, V.B.; Radočaj, O.F.; Pastor, O.P. Characteristics of blackberry and raspberry seeds and oils. Acta Period. Technol. 2012, 43, 1-9. [CrossRef]

12. Raczyk, M.; Bryś, J.; Brzezińska, R.; Ostrowska-Ligęza, E.; Wirkowska-Wojdyła, M.; Górska, A. Quality assessment of coldpressed strawberry, raspberry and blackberry seed oils intended for cosmetic purposes. Acta Sci. Pol. Technol. Aliment. 2021, 20, 127-133. [PubMed]

13. Harris, W.S. Are omega-3 fatty acids the most important nutritional modulators of coronary heart disease risk? Curr. Atheroscler. Rep. 2004, 6, 447-452. [CrossRef] [PubMed]

14. Mori, T.A.; Beilin, L.J.; Burke, V.; Morris, J.; Ritchie, J. Interactions between dietary fat, fish, and fish oils and their effects on platelet function in men at risk of cardiovascular disease. Arterioscler. Thromb. Vasc. Biol. 1997, 17, 279-286. [CrossRef] [PubMed]

15. Thies, F.; Garry, J.M.; Yaqoob, P. Association of n-3 polyunsaturated fatty acids with stability of atherosclerotic plaques: A randomised controlled trial. Lancet 2003, 361, 477-485. [CrossRef]

16. Heller, A.; Koch, T.; Schmeck, J.; van Ackern, K. Lipid mediators in inflammatory disorders. Drugs 1998, 55, 487-496. [CrossRef]

17. Kritschevsky, D.; Chen, S.C. Phytosterols-health benefits and potential concerns: A review. Nutr. Res. 2005, 25, 413-428. [CrossRef]

18. Seeram, N.P.; Adams, L.S.; Zhang, Y.; Lee, R.; Sand, D.; Scheuller, H.S.; Heber, D. Blackberry, black raspberry, blueberry, cranberry, red raspberry, and strawberry extracts inhibit growth and stimulate apoptosis of human cancer cells in vitro. J. Agric. Food Chem. 2006, 54, 9329-9339. [CrossRef] [PubMed]

19. Warner, K.; Mounts, T.L. Analysis of tocopherols and phytosterols in vegetable oils by HPLC with evaporative light-scattering detection. JAOCS 1990, 11, 827-831. [CrossRef]

20. Piironen, V.; Toivo, J.; Lampi, A.M. Plant sterols in cereals and cereal products. Cereal Chem. 2002, 79, 148-154. [CrossRef] 
21. Nawar, W.W. Chemistry. In Bailey's Industrial Oil E Fat Products; Hui, Y.H., Ed.; John Wiley \& Sons: New York, NY, USA, 1996; pp. 397-426.

22. Gunstone, F.D. Rapeseed and canola oil. In Production, Processing, Properties and Uses; CRC Press: Boca Raton, FL, USA, 2004.

23. Johansson, A.; Laakso, P.; Kallio, H. Characterization of seed oils of wild, edible Finnish berries. Zeitschrift für Lebensmittel Untersuchung und Forschung A 2007, 204, 300-307. [CrossRef]

24. Melnikov, S.M.; Seijen ten Hoorn, J.W.M.; Eikelenboom, A.P.A.M. Effect of phytosterols and phytostanols on the solubilization of cholesterol by dietary mixed micelles: An in vitro study. Chem. Phys. Lipids 2003, 2, 121-141. [CrossRef] [PubMed]

25. Omah, B.D.; Ladet, S.; Godfrey, D.V.; Liang, J.; Girard, B. Characteristics of raspberry (Rubus idaeus L.) seed oil. Food Chem. 2000, 69, 187-193. [CrossRef]

26. Tuberoso, C.I.G.; Kowalczyk, A.; Sarritzu, E.; Cabras, P. Determination of antioxidant compounds and antioxidant activity in commercial oilseeds for use. Food Chem. 2007, 103, 1494-1501. [CrossRef]

27. Kamal-Eldin, A. Effect of fatty acids and tocopherols on oxidative stability of vegetable oils. Eur. J. Lipid Sci. Technol. 2006, 108, 1051-1061. [CrossRef]

28. Kiralan, M.; Çalik, G.; Kiralan, S.; Ramadan, M.F. Monitoring stability and volatile oxidation compounds of cold-pressed flax seed, grape seed and black cumin seed oils upon photo-oxidation. J. Food Meas. Charact. 2018, 12, 616-621. [CrossRef]

29. Mildner-Szkudlarz, S.; Różańska, M.; Gaca, A.; Jeleń, H.H. Changes in volatile compound profiles of cold-pressed berry seed oils induced by roasting. LWT-Food Sci. Technol. 2021, 3, 111718. [CrossRef]

30. Morales, M.T.; Luna, G.; Aparicio, R. Comparative study of virgin olive oil sensory defects. Food Chem. 2005, 91, 293-301. [CrossRef]

31. National Center for Biotechnology Information. PubChem Compound Summary for CID 5364752, trans-2-Pentenal. Available online: https:/ / pubchem.ncbi.nlm.nih.gov / compound/trans-2-Pentenal (accessed on 28 November 2021).

32. National Center for Biotechnology Information. PubChem Compound Summary for CID 8058, Hexane. Available online: https:/ / pubchem.ncbi.nlm.nih.gov/ compound/Hexane (accessed on 28 November 2021).

33. Pedersen, T.; Sehested, K. Rate constants and activation energies for ozonolysis of isoprene methacrolein and methyl-vinyl-ketone in aqueous solution: Significance to the in-cloud ozonation of isoprene. Int. J. Chem. Kine 2001, 33, 182-190. [CrossRef]

34. National Center for Biotechnology Information. PubChem Compound Summary for CID 10423, Oxetane. Available online: https:/ / pubchem.ncbi.nlm.nih.gov/compound/Oxetane (accessed on 25 November 2021).

35. National Center for Biotechnology Information. PubChem Compound Summary for CID 31276, Isoamyl Acetate. Available online: https:/ / pubchem.ncbi.nlm.nih.gov/compound/Isoamyl-acetate (accessed on 25 November 2021).

36. National Center for Biotechnology Information. PubChem Compound Summary for CID 11173, 3-Methyl-2-buten-1-OL. Available online: https: / pubchem.ncbi.nlm.nih.gov/compound/3-Methyl-2-buten-1-OL (accessed on 25 November 2021).

37. National Center for Biotechnology Information. PubChem Compound Summary for CID 241, Benzene. Available online: https:/ / pubchem.ncbi.nlm.nih.gov/compound/Benzene (accessed on 25 November 2021).

38. National Center for Biotechnology Information. PubChem Compound Summary for CID 8857, Ethyl Acetate. Available online: https:/ / pubchem.ncbi.nlm.nih.gov/compound/Ethyl-acetate (accessed on 25 November 2021).

39. National Center for Biotechnology Information. PubChem Compound Summary for CID 6378, Propylene Oxide. Available online: https:/ / pubchem.ncbi.nlm.nih.gov/compound/Propylene-oxide (accessed on 25 November 2021).

40. National Center for Biotechnology Information. PubChem Compound Summary for CID 7809, p-Xylene. Available online: https:/ / pubchem.ncbi.nlm.nih.gov/compound/p-Xylene (accessed on 25 November 2021).

41. National Center for Biotechnology Information. PubChem Compound Summary for CID 6354, Ethylene oxide. Available online: https:/ / pubchem.ncbi.nlm.nih.gov/compound/Ethylene-oxide (accessed on 8 December 2021).

42. National Center for Biotechnology Information. PubChem Compound Summary for CID 957, 1-Octanol. Available online: https:/ / pubchem.ncbi.nlm.nih.gov/ compound/1-Octanol (accessed on 25 November 2021).

43. National Center for Biotechnology Information. PubChem Compound Summary for CID 6342, Acetonitrile. Available online: https:/ / pubchem.ncbi.nlm.nih.gov/compound/Acetonitrile (accessed on 25 November 2021).

44. National Center for Biotechnology Information. PubChem Compound Summary for CID 280, Carbon Dioxide. Available online: https:/ / pubchem.ncbi.nlm.nih.gov/compound/Carbon-dioxide (accessed on 25 November 2021).

45. National Center for Biotechnology Information. PubChem Compound Summary for CID 18554, 2-Ethylfuran. Available online: https:/ / pubchem.ncbi.nlm.nih.gov/compound/2-Ethylfuran (accessed on 25 November 2021).

46. Frankel, E.N. Lipid Oxidation: Mechanisms, Products and Biological Significance. J. Agric. Food Chem. 1984, 61, 1908-1917. [CrossRef]

47. Choe, E.; Min, D.B. Mechanisms and Factors for Edible Oil Oxidation. Compr. Rev. Food Sci. Food Saf. 2006, 5, 169-186. [CrossRef]

48. Prescha, A.; Grajzer, M.; Dedyk, M.; Grajeta, H. The Antioxidant Activity and Oxidative Stability of Cold-Pressed Oils. J. Am. Oil Chem. Soc. 2014, 91, 1291-1301. [CrossRef]

49. Azarbad, M.H.; Jeleń, H. Determination of hexanal—An indicator of lipid oxidation by static headspace gas chromatography (SHS-GC) in fat-rich food matrices. Food Anal. Methods 2015, 8, 1727-1733. [CrossRef]

50. Gaca, A.; Kludská, E.; Hradecký, J.; Hajšlová, J.; Jeleń, H.H. Changes in Volatile Compound Profies in Cold-Pressed Oils Obtained from Various Seeds during Accelerated Storage. Molecules 2021, 26, 285. [CrossRef] [PubMed] 
51. AOCS. Determination of cis-, trans-, saturated, monounsaturated and polyunsaturated fatty acids in vegetable or non-ruminant animal oils and fats by capillary GLC. In Official Methods and Recommended Practices of the AOCS, 6th ed.; Official Method Ce 1h-05; Firestone, D., Ed.; AOCS Press: Champaign, IL, USA, 2005; pp. 1-29.

52. Gracka, A.; Raczyk, M.; Hradecký, J.; Hajslova, J.; Jeziorski, S.; Karlovits, G.; Michalak, B.; Bąkowska, N.; Jeleń, H. Volatile compounds and other indicators of quality for cold-pressed rapeseed oils obtained from peeled, whole, flaked and roasted seeds. Eur. J. Lipid Sci. Technol. 2017, 119, 1600328. [CrossRef]

53. Gąsior, R.; Pieszka, M.; Brzóska, F. Validation of a method for simultaneous determination of tocopherols and tocotrienols in cereals using normal phase HPLC. J. Anim. Feed Sci. 2009, 18, 173-192. [CrossRef]

54. AOCS. Determination of the composition of the sterol fraction of animal and vegetable oils and fats by TLC and capillary GLC. In Methods and Recommended Practices of the AOCS, 6th ed.; Official Method Ch 6-91; Firestone, D., Ed.; AOCS Press: Champaign, IL, USA, 1997; pp. 1-5.

55. AOCS. Acid value. In Official Methods and Recommended Practices of the AOCS, 6th ed.; Official Method Te 1a-64; Firestone, D., Ed.; AOCS Press: Champaign, IL, USA, 2009; p. 1.

56. AOCS. Peroxide value Acetic Acid-Isooctane Method. In Official Methods and Recommended Practices of the AOCS, 6th ed.; Official Method Cd 8b-90; Firestone, D., Ed.; AOCS Press: Champaign, IL, USA, 2009; pp. 1-3. 